\title{
CHICAGO JOURNALS
}

Foliar Reflectance and Vector Analysis Reveal Nutrient Stress in Prey-Deprived Pitcher Plants ( Nepenthes rafflesiana)

Author(s): Jonathan A. Moran and Alison J. Moran

Reviewed work(s):

Source: International Journal of Plant Sciences, Vol. 159, No. 6 (November 1998), pp. 996-1001

Published by: The University of Chicago Press

Stable URL: http://www.jstor.org/stable/10.1086/314086

Accessed: 04/03/2013 20:10

Your use of the JSTOR archive indicates your acceptance of the Terms \& Conditions of Use, available at

http://www.jstor.org/page/info/about/policies/terms.jsp

JSTOR is a not-for-profit service that helps scholars, researchers, and students discover, use, and build upon a wide range of content in a trusted digital archive. We use information technology and tools to increase productivity and facilitate new forms of scholarship. For more information about JSTOR, please contact support@jstor.org. 
Int. J. Plant Sci. 159(6):996-1001. 1998.

(C) 1998 by The University of Chicago. All rights reserved.

1058-5893/98/5906-0011\$03.00

\title{
FOLIAR REFLECTANCE AND VECTOR ANALYSIS REVEAL NUTRIENT STRESS IN PREY-DEPRIVED PITCHER PLANTS (NEPENTHES RAFFLESIANA)
}

\author{
Jonathan A. Moran and Alison J. Moran² \\ Department of Biology, Universiti Brunei Darussalam, Bandar Seri Begawan 2028, Brunei
}

\begin{abstract}
Pitcher plants of the genus Nepenthes trap invertebrate prey in pitchers formed from modified leaf tips. This study investigates the benefits of carnivory to Nepenthes rafflesiana, a common Bornean lowland species. Plants were denied prey capture in their natural habitat for $18 \mathrm{wk}$ and were compared with a control group that was allowed to trap, digest, and assimilate prey as usual over the same period. Resource limitation was demonstrated in prey-deprived plants, which produced significantly fewer and smaller pitchers than did control plants. Analysis of foliar spectral reflectance showed increased reflectance within part (608-738 nm) of the photosynthetically active wave band in the prey-deprived plants, signifying a reduction in chlorophyll content. Decreased reflectance at $550 \mathrm{~nm}$ in the prey-deprived plants also indicated increased production of anthocyanins, denoting possible nitrogen or phosphorus limitation. Although no difference was found in tissue concentrations of nitrogen or phosphorus between treatments, vector analysis identified a reduction in content of both elements as a result of reduced biomass production in prey-deprived plants. Our findings demonstrate the key role carnivory plays in the nutrition of this species in its natural habitat.
\end{abstract}

\section{Introduction}

In common with other carnivorous plants, pitcher plants of the genus Nepenthes (family Nepenthaceae) are found predominantly in sunny and wet or waterlogged habitats that are believed to be nutrient limited (Lüttge 1983; Benzing 1987). Nepenthes pitchers have evolved to trap, digest, and absorb the breakdown products of invertebrates and in some species have developed floral traits to attract anthophilous (flowervisiting) insects. For example, those of Nepenthes rafflesiana Jack, a common Bornean species, possess both a flower-like fragrance and ultraviolet patterns that have been shown to contribute to prey attraction (Moran 1996). The production of elaborate and complex trapping mechanisms indicates strong evolutionary pressure to augment the more usual mode of nutrient uptake via the roots with nutrients from animal prey.

The family Nepenthaceae comprises 82 species (Jebb and Cheek 1997), making it the largest pitcher plant family, and one of the larger taxa among the carnivorous plants (Juniper et al. 1989; Clarke 1997). However, while the benefits of prey capture are documented for other carnivorous plant families (Sarraceniaceae [Christensen 1976; Chapin and Pastor 1995], Lentibulariaceae [Aldenius et al. 1983], Droseraceae [Chandler and Anderson 1976; Wilson 1985; Thum 1988; Schulze and Schulze 1990; Gibson 1991; Karlsson and Pate 1992]), to date there have been no published quantitative studies on Nepen-

\footnotetext{
${ }^{1}$ Author for correspondence and reprints. Current address: Department of Biology, University of Victoria, P.O. Box 3020, Victoria, British Columbia V8W 3N5, Canada; fax 250-721-7120.

${ }^{2}$ Current address: Department of Biochemistry and Microbiology, University of Victoria, P.O. Box 3055, Victoria, British Columbia V8W 3P6, Canada.

Manuscript received March 1998; revised manuscript received May 1998.
}

thes species to investigate this aspect of their biology. We explored this question by assessing the consequences of zero prey capture to N. rafflesiana in its natural habitat via analysis of pitcher production, tissue nutrient status, and foliar reflectance. Nepenthes rafflesiana attracts and catches a wide spectrum of invertebrate prey in its pitchers, although the dominant prey group are Formicidae (Moran [1996] provides an account of the prey spectrum of this species in Brunei). The null hypotheses were that denial of prey would have no significant effect on growth performance, tissue nutrient status (nitrogen and phosphorus), or foliar chlorophyll content in plants that were denied prey.

\section{Material and Methods}

The investigation was carried out in a small $\left(<300 \mathrm{~m}^{2}\right)$ area of degraded coastal heath forest in Brunei, northwest Borneo $\left(4^{\circ} 44^{\prime} \mathrm{N}, 114^{\circ} 36^{\prime} \mathrm{E}\right)$, overlying an albic arenosol (heavily leached, white sand) on a Pleistocene marine terrace (Brünig 1974). The vegetation was low scrub dominated by Ploiarium alternifolium Melchior (Theaceae) and Dillenia suffruticosa Griff. Martelli (Dilleniaceae). In March 1995, 30 Nepenthes rafflesiana plants were selected for study. Small plants $(<0.5$ $\mathrm{m}$ height) with one to three live pitchers were chosen to minimize the possibility of nutrient reserves reducing the effect of prey deprivation on the treated individuals. Since all plants used in the study were necessarily small and prereproductive, sex was impossible to determine (Dellaporta and CalderaUrrea 1993). The following two treatments were allocated randomly. (1) The live pitchers of 15 plants were emptied of their contents by rinsing with deionized water into a container that was emptied outside of the study site. The pitchers were then packed with a wad of cotton wool moistened with deionized water to provide a barrier to prey entry without damaging the pitcher in any observable way. Before insertion, the cotton 
wool was soaked and rinsed three times in deionized water over a 48 -h period to remove possible contaminating nutrient elements. The plants were examined at $10-14-\mathrm{d}$ intervals throughout the 18 -wk course of the study, and any newly opened pitchers were treated in the same way. (2) The remaining 15 plants served as controls. The pitchers were not emptied and were allowed to catch prey over the period of the experiment. At the end of the study, all plants were harvested. The number and length $(\mathrm{cm})$ of all live pitchers were recorded for each plant at the beginning and end of the study. For plants with no live pitchers at the end of the study, mean pitcher length was recorded as zero. Because of mortality losses, only 13 control and 14 experimental plants were harvested. A further two experimental plants were removed from the study after they were found to be linked by runners to larger plants.

All roots and live leaves (lamina and tendril only) were removed from each plant and washed briefly in deionized water, dried at $60^{\circ} \mathrm{C}$ for $48 \mathrm{~h}$, and ground to pass a 40 -mesh screen. Pitchers were not assayed as it would have been impossible to exclude the possibility of nutrient contamination from prey remains in those of the control plants. A Kjeldahl digestion was carried out on a random subsample of the leaf and root material from each plant, using a Lachat model BD 46 block digestor (Lachat Instruments, Milwaukee) with concentrated sulfuric acid and a potassium sulfate/copper sulfate catalyst. The resulting solutions were analyzed using a Lachat QuickChem Flow Injection Analyzer (Lachat Instruments, Milwaukee), employing the indophenol-blue reaction for total nitrogen and the acid molybdate reaction for total phosphorus (Allen 1989). Precision was assessed by calculating coefficients of variation (CVs) for results from six replicates of the same sample (Sokal and Rohlf 1981). The CVs for nitrogen and phosphorus concentration were $3 \%$ and $7 \%$, respectively. Accuracy was determined by comparison with external reference materials (Standard Reference Material \#1515 [apple leaves], National Institute of Standards and Technology, U.S.A., for nitrogen; external material from Department of Chemistry, Universiti Brunei Darussalam, for phosphorus). Observed values deviated from certified values by the following amounts: nitrogen $+4 \%$, phosphorus $-10 \%$.

From the results of the chemical analyses and morphological measurements, a vector diagram was constructed (Timmer 1991) to represent graphically the effects of prey deprivation on foliar nutrient concentration (unit mass of nutrient per unit mass of tissue), dry matter production, and nutrient content (nutrient concentration $\times$ mass of tissue). Mean control values for unit dry weight, nutrient concentration, and nutrient content were normalized to represent $100 \%$, and the mean preydeprived values were calculated and plotted in relation to these (Haase and Rose 1995). Since there were no direct measurements of biomass production made, an estimate was derived by multiplying mean pitcher number by mean pitcher length to give a productivity index. This was deemed valid, as it is relative changes that are important in vector analysis, and a significant allometric relationship exists between pitcher length and dry weight in this species $(R=0.76, P<0.001, n=34$; J. Moran, unpublished data).

Analysis of foliar reflectance has proven effective in identifying stress from a number of agents (e.g., ozone, drought, pathogens) for several plant species (Carter 1993, 1994; Carter and Miller 1994) and relies on the fact that absorption of radiation by leaves between ca. 400 and $700 \mathrm{~nm}$ results primarily from chlorophyll (Knipling 1970). According to the Beer-Lambert Law, the fraction of incident radiation absorbed is proportional to the number of absorbing molecules in its path (Salisbury and Ross 1992), and thus a reduction in foliar chlorophyll content will result in increased reflectance in this wave band (Carter et al. 1992; Mariotti et al. 1996). As chlorophyll content decreases, absorptance within the 400-700$\mathrm{nm}$ wave band will decrease and reflectance will increase first at those wavelengths in which absorptance by the pigments is relatively weak. Only after further reduction in pigment concentration will decreased absorptance be noticed at wavelengths in which the pigments are strongly absorptive (Carter and Miller 1994). Thus, a ratio of reflectance at a stress-sensitive wavelength to one at an insensitive wavelength can be used to compare stress levels between groups via foliar chlorophyll content. Reflectance analysis was carried out as follows: before processing for nutrient assays, the youngest mature leaf possessing a fully developed pitcher was removed from each plant and a scan of reflected energy $\left(\mathrm{W} \mathrm{m}^{-2}\right)$ was carried out on the center of the adaxial (upper) side of the lamina, using a LI 1800 Spectroradiometer with an 1800-12S Integrating Sphere (Li-Cor, Lincoln, Nebr.) under illumination by a halogen lamp. The scan was made at 2-nm resolution from $400 \mathrm{~nm}$ (violet) to $1100 \mathrm{~nm}$ (infrared). Leaves were selected to obtain a sample population of approximately the same stage of development, as reflectance characteristics change with leaf age (Gausman and Quisenberry 1990). Percentage reflectance at each wavelength was then determined by dividing the measured reflected radiation value from the leaf by that from a standard reference material (barium sulfate, Li-Cor, Lincoln, Nebr.), the reflectance of which was assumed to be $100 \%$, and multiplying by 100 . Sensitivity analysis (sensu Carter 1993, 1994) was then conducted to determine which wavelengths were most responsive to the effects of prey deprivation. Sensitivity was calculated in two stages. First, the mean percentage reflectance values of the control plants were subtracted from those of the prey-deprived plants at each wavelength (fig. $2 a$ ) to give reflectance difference (fig. 2b). Sensitivity at each wavelength was then calculated by dividing the reflectance difference values in figure $2 b$ by the reflectance values of the control plants at each wavelength (fig. $2 c$ ). On the basis of the results of the sensitivity analysis, reflectance ratios were determined and compared between experimental and control plants.

All analyses were carried out using the SigmaStat version 2.0 statistical package (Jandel Scientific, San Rafael, Calif.). For $t$-tests, data were first analyzed for normality and homogeneity of variance. Nonnormal data were square-roottransformed before running the test, and in cases where transformation was ineffective, the nonparametric Mann-Whitney $U$-test was employed (Sokal and Rohlf 1981).

\section{Results}

By the end of the 18-wk study period, prey-deprived plants produced significantly smaller pitchers (ca. 45\%) and in smaller numbers (ca. 46\%), compared with the control group (table 1). There were no significant differences in root or leaf 
Table 1

Summary of Response Categories between Nepenthes rafflesiana Plants without and with Prey Input over an 18-wk Period

\begin{tabular}{|c|c|c|c|c|}
\hline Response & Without prey & With prey & $\mathrm{df}$ & $P$ \\
\hline \multicolumn{5}{|l|}{ Total pitcher number per plant: } \\
\hline Initial...$\ldots \ldots \ldots \ldots \ldots$ & $1.4(0.2)$ & $1.3(0.1)$ & 23 & $\mathrm{~ns}^{\mathrm{a}}$ \\
\hline Final $\ldots \ldots \ldots \ldots \ldots \ldots$ & $0.7(0.2)$ & $1.3(0.2)$ & 23 & 0.036 \\
\hline \multicolumn{5}{|l|}{ Mean pitcher length per plant $(\mathrm{mm})$ : } \\
\hline Initial $\ldots \ldots \ldots \ldots+\ldots \ldots \ldots$ & $7.9(0.3)$ & $8.6(0.6)$ & 23 & ns \\
\hline Final $\ldots \ldots+\ldots \ldots+\cdots$ & $4.5(1.1)$ & $8.3(0.6)$ & 23 & 0.005 \\
\hline \multicolumn{5}{|l|}{ Nitrogen wt/wt (\%): } \\
\hline Leaf & $0.52(0.04)$ & $0.57(0.04)$ & 23 & ns \\
\hline Root $\ldots \ldots \ldots \ldots \ldots$ & $0.18(0.02)$ & $0.17(0.01)$ & 22 & ns \\
\hline \multicolumn{5}{|l|}{ Phosphorus wt/wt (\%): } \\
\hline Leaf $\ldots \ldots \ldots \ldots \ldots \ldots$ & $0.077(0.007)$ & $0.085(0.008)$ & 23 & ns \\
\hline Root $\ldots \ldots \ldots \ldots \ldots \ldots$ & $0.013(0.001)$ & $0.015(0.003)$ & 22 & $n s^{b}$ \\
\hline \multicolumn{5}{|l|}{ Foliar reflectance ratios $(\mathrm{nm})$ : } \\
\hline$\lambda 692: 420 \quad \ldots \ldots \ldots \ldots \ldots \ldots \ldots \ldots$ & $3.25(0.16)$ & $2.76(0.10)$ & 23 & 0.019 \\
\hline$\lambda 692: 760 \quad \ldots$. & $0.25(0.01)$ & $0.21(0.00)$ & 23 & 0.015 \\
\hline$\lambda 636: 420 \quad \ldots \ldots \ldots \ldots \ldots \ldots \ldots \ldots$ & $2.84(0.12)$ & $2.46(0.09)$ & 23 & 0.018 \\
\hline$\lambda 636: 760 \ldots$ & $0.22(0.01)$ & $0.19(0.00)$ & 23 & 0.014 \\
\hline
\end{tabular}

Note. Values denote mean ( \pm SE in parentheses). Unless otherwise noted, $P$ was determined using a $t$-test. ns $=$ not significant (i.e., $P>0.05$ ).

${ }^{a}$ Mann-Whitney $U$-test used.

${ }^{\mathrm{b}}$ Data were square-root-transformed.

tissue concentrations of nitrogen or phosphorus between groups (table 1), although foliar content of both elements in prey-deprived plants decreased relative to controls (by 67\% and $78 \%$, respectively, for nitrogen and phosphorus; fig. 1). Prey-deprived plants showed significantly higher foliar reflectance than the controls in the wave band 608-738 nm $(P<$ $0.05, t$-test, denoted by the shaded region in fig. $2 b, c)$, and a tendency (not statistically significant) toward reduced reflectance at $550 \mathrm{~nm}$ (fig. $2 a, b$ ). Significant sensitivity maxima occurred at $636 \mathrm{~nm}$ and $692 \mathrm{~nm}$ (fig. 2c). Foliar reflectance ratios were significantly higher in prey-deprived plants for 692 : $420 \mathrm{~nm}, 692$ : $760 \mathrm{~nm}, 636: 420 \mathrm{~nm}$ and $636: 760 \mathrm{~nm}$ (table 1 ), indicating a reduction in foliar chlorophyll content (Carter et al. 1992; Mariotti et al. 1996).

\section{Discussion}

Initially, the lack of significant differences in tissue concentrations of nitrogen and phosphorus between the experimental and control groups appears at odds with the other findings of this study, and with those of studies on other carnivorous plant species. Increased foliar concentrations of these elements as a result of digesting insect prey have been reported for Sarracenia spp. (Christensen 1976; Chapin and Pastor 1995), Pinguicula vulgaris (Aldenius et al. 1983), and Drosera sp. (Chandler and Anderson 1976). However, analysis of nutrient concentration (the amount of the element in a unit amount of tissue) cannot always be relied on to identify cases of nutrient deficiency, especially with regard to nitrogen (Comerford and Fisher 1984). This is primarily because of the fact that under conditions of resource limitation, plants are able to maintain critical foliar nutrient concentrations by a reduction in growth rate (Farnum et al. 1983). Because there was a decrease in

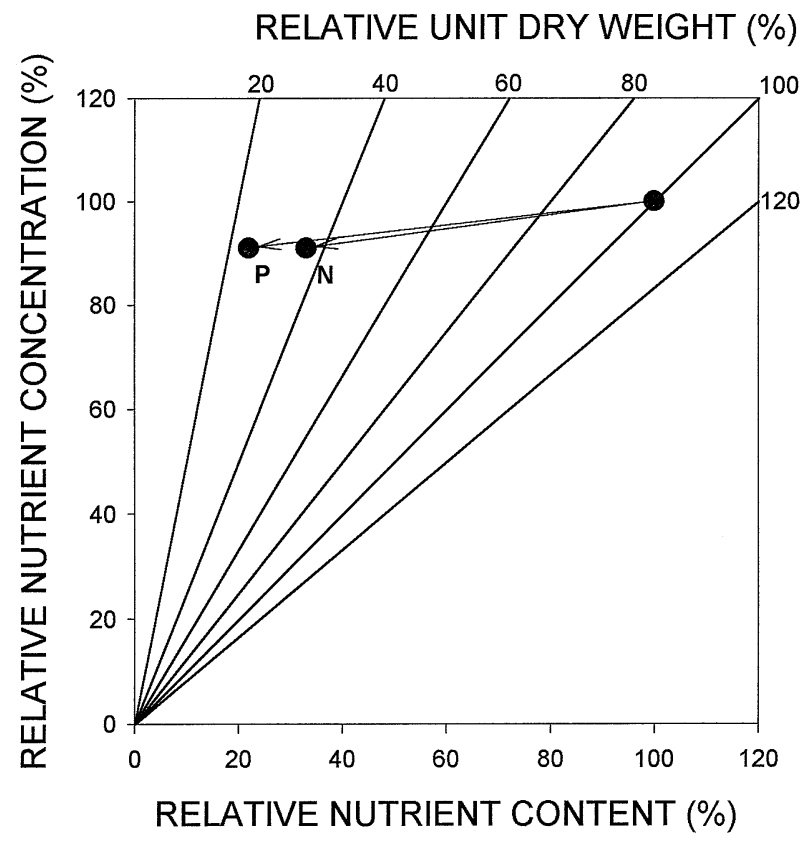

Fig. 1 Vector diagram of mean foliar nutrient concentration (unit mass of nutrient per unit dry weight of tissue), nutrient content (nutrient concentration $\times$ dry weight of tissue), and dry weight for preydeprived plants, relative to the mean values for controls (point at right, no label), which are normalized to $100 \%$ for all three axes. $n=12$, 13 for prey-deprived and control groups, respectively. $N=$ nitrogen, $P=$ phosphorus. Arrows indicate direction of change relative to the control group; length of arrow is proportional to the magnitude of change. 

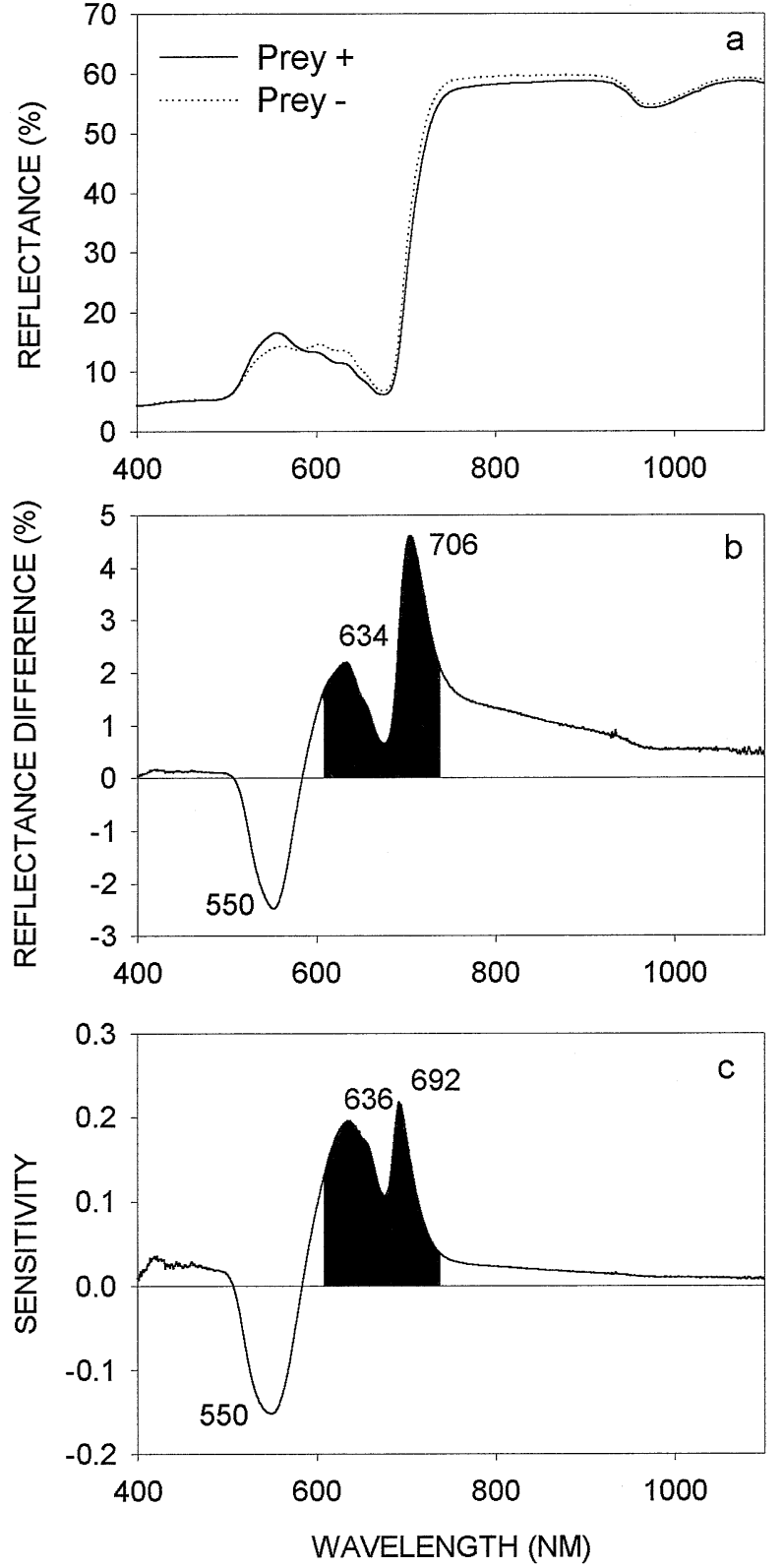

Fig. 2 Reflectance response of adaxial surface of leaves from preydeprived plants $(n=12)$ compared with controls $(n=13)$. Methodology is after Carter $(1993,1994)$. a, Percentage reflectance compared to a barium sulfate reference surface (assumed to be $100 \%$ ). The solid and dotted lines denote mean values for control and prey-deprived plants, respectively. $b$, Percentage reflectance difference, produced by subtracting the mean values for control plants from those of the preydeprived plants. $c$, Sensitivity (no units; \%/\%), produced by dividing percentage reflectance difference $(b)$ by percentage reflectance values for control plants (solid line, $a$ ). The shaded areas in $b$ and $c$ indicate the regions for which there was a significant difference in percentage reflectance between experimental and control plants $(P<0.05, t$-test $)$. biomass production in terms of pitcher number and size, the nutrient content (i.e., concentration $\times$ biomass) was lower in the prey-deprived plants. Vector analysis provides a graphical representation of this effect (Timmer 1991; Haase and Rose 1995). Since biomass estimates were calculated by indirect means (based on an allometric relationship between pitcher length and dry weight), it must be stressed that the vector analysis approach as used here is qualitative rather than quantitative, and therefore useful in identifying general trends only. The direction of the vector line denotes the change relative to the control group, its length denoting the magnitude of the change. The content of both nitrogen and phosphorus is reduced in prey-deprived plants relative to the controls, and the effect of prey deprivation appears to be greater for phosphorus than for nitrogen (fig. 1). There can be little doubt that the prey-deprived plants were nutrient-stressed, resulting in a reduction in both size and number of pitchers. The three other possible stress candidates, light limitation, water stress, and heat stress, can be ruled out since both experimental and control groups were randomly dispersed within a small area $(<300$ $\mathrm{m}^{2}$ ), and were thus subject to an equivalent range of edaphic and radiation regimes. It is unlikely that prey-deprived plants were heat-stressed relative to the controls since the cotton wool in the blocked pitchers was kept moist over the course of the experiment. Therefore, the results support the hypothesis that in the natural habitat, biomass production in Nepenthes rafflesiana depends largely on nutrient input from prey. Circumstantial support for this conclusion comes from a survey of male and female $N$. rafflesiana plants in the same area, which showed that females produced significantly more pitchers before flowering for the first time than did males (mean \pm $\mathrm{SE}=23.1 \pm 1.3$ for males, $29.5 \pm 1.8$ for females, $P=$ 0.007 using $t$-test, $n=17$ for each sex; J. Moran, unpublished data). Since female plants have a higher nutritional requirement than males for reproduction (Stephenson and Bertin 1983), this result would be expected if prey capture by the pitchers represented a significant source of nutrients.

The foliar reflectance technique identified nutrient stress in the prey-deprived plants, proving a superior method to that of tissue nutrient concentration analysis alone for this species. Sensitivity analysis showed a maximum at $692 \mathrm{~nm}$, which corresponds closely to the fact that chlorophyll is weakly absorptive in that region (Chappelle et al. 1992) and is remarkably close to the sensitivity maximum of $695 \mathrm{~nm}$ shown by Carter (1994) for multiple species/multiple stress comparisons. A second sensitivity peak occurred at $636 \mathrm{~nm}$, which corresponds to another region of low absorptance. There is strong absorption by chlorophyll and associated pigments between ca. $415 \mathrm{~nm}$ and $420 \mathrm{~nm}$ (Chappelle et al. 1992), and so absorptance within this band should be less sensitive to stressrelated reductions in foliar chlorophyll content. This was found to be the case in the current study and corresponds with the findings of Carter (1994) and Carter and Miller (1994) for absorptance at $420 \mathrm{~nm}$. Wavelengths outside of the absorption spectra of chlorophylls can also be used as insensitive reference points for reflectance ratios, and following Carter (1993, 1994), we used $760 \mathrm{~nm}$, a wavelength that was also shown to be insensitive in the current study. The concept of a reduction in chlorophyll content and consequent reduction in photosynthetic potential concurs with the morphological find- 
ings of the study, i.e., a reduced capacity for biomass production in plants denied nutrient uptake via carnivory.

Although not significant at $P=0.05$, there appears to be a tendency toward decreased reflectance at $550 \mathrm{~nm}$ (green) in the leaves of prey-deprived plants relative to the controls. Since chlorophyll shows a reflectance maximum at this wavelength (Chappelle et al. 1992; Buschmann and Nagel 1993), the effect may result entirely from a reduction of the pigment content. Another possibility is that the effect is the result of reduced nitrogen content in the experimental plants. Tsay et al. (1982) demonstrated an inverse relationship between foliar nitrogen content and reflectance at $540 \mathrm{~nm}$ in loblolly pine (Pinus taeda L.). We believe, however, that at least part of the effect results from increased foliar concentrations of anthocyanins, red or blue pigments with absorption maxima in the wave band 500-550 nm (Jurd 1962). Red staining resulting from these compounds is commonly observed on the leaves of N. rafflesiana plants in their natural habitat (J. Moran, personal observation). Two factors have been shown to promote anthocyanin production in plants. The first is light intensity (Sato et al. 1996), which is unlikely to have been important in the current study, given that both experimental and control groups were presumed to experience an equivalent range of light climates. The second is nutrient limitation, specifically, nitrogen or phosphorus (Bongue-Bartelsman and Phillips 1995; Hodges and Nozzolillo 1996; Sato et al. 1996), and it is possible that the trend toward increased production of foliar anthocyanins results from deficiencies in one or both of these elements, a hypothesis corroborated by the results of the vector analysis.

To conclude, the results of the study demonstrate the importance of prey-mediated nutrition to growth of N. rafflesiana in its natural environment. It is worth bearing in mind that the conclusion reached for this species may not necessarily hold to the same degree across the entire genus, given the apparent diversity of feeding strategies employed among individual species (Kato et al. 1993; Moran 1996; Clarke 1997).

\section{Acknowledgments}

We thank W. Booth for help with the reflectance analysis, G. Carter for valuable information on sensitivity analysis, and the Department of Chemistry, Universiti Brunei Darussalam (UBD) for provision of external reference material. B. Hawkins and D. Ormrod commented on earlier drafts of the article. The work was undertaken during a research fellowship from the Department of Biology, UBD. This article is dedicated to Ann Elizabeth Moran (1941-1998).

\section{Literature Cited}

Aldenius J, B Carlsson, S Karlsson 1983 Effects of insect trapping on growth and nutrient content of Pinguicula vulgaris $\mathrm{L}$. in relation to the nutrient content of the substrate. New Phytol 93:53-59.

Allen SE 1989 Chemical analysis of ecological materials. 2d ed. Blackwell Scientific, Oxford.

$\rightarrow$ Benzing DH 1987 The origin and rarity of botanical carnivory. TREE 2:364-369.

Bongue-Bartelsman M, DA Phillips 1995 Nitrogen stress regulates gene expression of enzymes in the flavonoid biosynthetic pathway of tomato. Plant Physiol Biochem 33:539-546.

Brünig EF 1974 Ecological studies in the Kerangas forests of Sarawak and Brunei. Borneo Literature Bureau, Kuching.

$\rightarrow$ Buschmann C, E Nagel 1993 In vivo spectroscopy and internal optics of leaves as basis for remote sensing of vegetation. Int J Remote Sens 14:711-722.

$\rightarrow$ Carter GA 1993 Responses of leaf spectral reflectance to plant stress. Am J Bot 80:239-243.

$\rightarrow-1994$ Ratios of leaf reflectances in narrow wavebands as indicators of plant stress. Int J Remote Sens 15:697-703.

$\rightarrow$ Carter GA, RL Miller 1994 Early detection of plant stress by digital imaging within narrow stress-sensitive wavebands. Remote Sens Environ 50:295-302.

$\rightarrow$ Carter GA, RJ Mitchell, AH Chappelka, CH Brewer 1992 Response of leaf spectral reflectance in loblolly pine to increased atmospheric ozone and precipitation acidity. J Exp Bot 43:577-584.

$\rightarrow$ Chandler GE, JW Anderson 1976 Studies on the nutrition and growth of Drosera species with reference to the carnivorous habit. New Phytol 76:129-141.

Chapin CT, J Pastor 1995 Nutrient limitations in the northern pitcher plant Sarracenia purpurea. Can J Bot 73:728-734.

$\rightarrow$ Chappelle EW, MS Kim, JE McMurtrey 1992 Ratio analysis of reflectance spectra (RARS): an algorithm for the remote estimation of the concentrations of chlorophyll $a$, chlorophyll $b$, and carotenoids in soybean leaves. Remote Sens Environ 39:239-247.

Christensen NL 1976 The role of carnivory in Sarracenia flava L., with regard to specific nutrient deficiencies. J Elisha Mitchell Sci Soc 92:144-147.

Clarke C 1997 Nepenthes of Borneo. Natural History Publications, Kota Kinabalu.

$\rightarrow$ Comerford NB, RF Fisher 1984 Using foliar analysis to classify nitrogen-deficient sites. Soil Sci Soc Am J 48:910-913.

$\rightarrow$ Dellaporta SL, A Calderon-Urrea 1993 Sex determination in flowering plants. Plant Cell 5:1241-1251.

$\rightarrow$ Farnum P, T Timmis, JL Kulp 1983 Biotechnology of forest yield. Science 219:694-702.

Gausman HW, JE Quisenberry 1990 Spectrophotometric detection of plant leaf stress. Pages 257-280 in F Katterman, ed. Environmental injury to plants. Academic Press, New York.

$\rightarrow$ Gibson TC 1991 Competition among threadleaf sundews for limited insect resources. Am Nat 138:785-789.

Haase DL, R Rose 1995 Vector analysis and its use for interpreting plant nutrient shifts in response to silvicultural treatments. For Sci 41:54-66.

Hodges DM, C Nozzolillo 1996 Anthocyanin and anthocyanoplast content of cruciferous seedlings subjected to mineral nutrient deficiencies. J Plant Physiol 147:749-754.

Jebb M, M Cheek 1997 A skeletal revision of Nepenthes (Nepenthaceae). Blumea 42:1-106.

Juniper BE, RJ Robins, D Joel 1989 The carnivorous plants. Academic Press, London.

Jurd L 1962 Spectral properties of flavonoid compounds. Pages 107-155 in TA Geissman, ed. The chemistry of flavonoid compounds. Macmillan, New York.

$\rightarrow$ Karlsson PS, JS Pate 1992 Contrasting effects of supplementary feeding of insects or mineral nutrients on the growth and nitrogen and phosphorus economy of pygmy species of Drosera. Oecologia 92: 8-13.

Kato M, M Hotta, R Tamin, T Itino 1993 Inter- and intra-specific variation in prey assemblages and inhabitant communities in $\mathrm{Ne}$ penthes pitchers in Sumatra. Trop Zool 6:11-25.

$\rightarrow$ Knipling EB 1970 Physical and physiological basis for the reflectance 
of visible and near-infra-red radiation from vegetation. Remote Sens Environ 1:155-159.

Lüttge U 1983 Ecophysiology of carnivorous plants. Pages 489-517 in OL Lange, PS Nobel, CB Osmond, H Ziegler, eds. Encyclopedia of plant physiology. Vol 12C. Springer, Berlin.

$\rightarrow$ Mariotti M, L Ercoli, A Masoni 1996 Spectral properties of irondeficient corn and sunflower leaves. Remote Sens Environ 58: 282-288.

$\rightarrow$ Moran JA 1996 Pitcher dimorphism, prey composition and the mechanisms of prey attraction in the pitcher plant Nepenthes rafflesiana in Borneo. J Ecol 84:515-525.

Salisbury FB, CW Ross 1992 Plant physiology. 4th ed. Wadsworth, Belmont, Calif.

$\rightarrow$ Sato K, M Nakayama, J Shigeta 1996 Culturing conditions affecting the production of anthocyanin in suspended cell cultures of strawberry. Plant Sci 113:91-98.

$\rightarrow$ Schulze W, E-D Schulze 1990 Insect capture and growth of the insectivorous Drosera rotundifolia L. Oecologia 82:427-429.
Sokal RR, FJ Rohlf 1981 Biometry. 2d ed. W. H. Freeman, New York. Stephenson AG, RI Bertin 1983 Male competition, female choice, and sexual selection in plants. Pages 109-149 in L Real, ed. Pollination biology. Academic Press, New York.

$\rightarrow$ Thum M 1988 The significance of carnivory for the fitness of Drosera in its natural habitat. 1. The reactions of Drosera intermedia and D. rotundifolia to supplementary feeding. Oecologia 75: 472-480.

Timmer VR 1991 Interpretation of seedling analysis and visual symptoms. Pages 113-134 in R van den Driessche, ed. Mineral nutrition of conifer seedlings. CRC, Boca Raton, Fla.

$\rightarrow$ Tsay M-L, DH Gjerstad, GR Glover 1982 Tree leaf reflectance: a promising technique to rapidly determine nitrogen and chlorophyll content. Can J For Res 12:788-792.

$\rightarrow$ Wilson SD 1985 The growth of Drosera intermedia in nutrient-rich habitats: the role of insectivory and interspecific competition. Can J Bot 63:2468-2469. 